\title{
An Occupational Study in Nurses: Prevalence of Thyroid Nodules and Cancer in Comparison to Health Check-up Female
}

\author{
Kyung Hee $\mathrm{Kim}^{1,2} \cdot$ Seung Hoon Woo ${ }^{1,3}$ \\ ${ }^{1}$ Department of Otolaryngology, ${ }^{2}$ Department of Nursing, Graduate School, ${ }^{3}$ Institute of Health Sciences, Gyeongsang National University,
} Jinju, Korea

Objectives. It is known that a great extent of radiation is emitted from the medical instruments used in hospitals and that radiation exposure can cause thyroid cancer. However, the correlation between occupational radiation exposure in hospitals and thyroid disease is not extensively recognized.

Methods. The subjects of the study were female nurses, who worked at a single hospital and female, who had undergone a health examination at the same hospital during the same period. The 1,024 nurses and 2,631 healthy women were enrolled for the present study. All the participants were screened using thyroid ultrasonography, and fine-needle aspiration \& cytology was performed on potentially malignant nodules.

Results. Thyroid nodules were present in 315 nurses (30.8\%) and 1,023 health check-up female (38.9\%). Typically, 107 nurses $(10.4 \%)$ and 201 health check-up female (7.6\%) had suspicious nodule and were further tested with ultrasonography guided fine-needle aspiration \& cytology. The 16 nurses (1.6\%) and 38 health check-up female (1.4\%) were diagnosed with thyroid cancer. The prevalence of thyroid nodules was enhanced in both the groups and a significant increase was noted in health check-up female group $(P<0.05)$; however, no difference was seen in the incidence of thyroid cancer in both the groups $(P>0.05)$.

Conclusion. In our study, working in a hospital does not increase the prevalence of thyroid nodules or thyroid cancer.

Keywords. Nurses; Prevalence; Thyroid Carcinoma; Radiation; Occupations

\section{INTRODUCTION}

Thyroid nodules are very common in the broad-spectrum population, with an estimated prevalence of $4 \%-7 \%$ [1-4]. However, the prevalence of these nodules can vary depending on the size and location, the thickness of the neck, and physician's skill in detecting them [5-12]. It has been reported that the prevalence of nodules in normal Korean female based on thyroid ultrasonography was $25.3 \%$ to $42.2 \%$ [13]. However, the number of

\footnotetext{
- Received July 8, 2015

Revised July 30, 2015

Accepted September 2, 2015

- Corresponding author: Seung Hoon Woo

Department of Otolaryngology, Gyeongsang National University School of

Medicine, 79 Gangnam-ro, Jinju 52727, Korea

Tel: +82-55-750-8173, Fax: +82-55-772-8170

E-mail: lesaby@hanmail.net
}

thyroid nodules increases with age in female [13]. The risk of a malignancy developing from a thyroid nodule is reportedly higher in children, males, adults less than 20 years of age or those greater than 60 years of age, and in patients with a history of head and neck irradiation [14-19].

A wide range of people in many occupations are exposed to radiation. In recent years, there has been a rapid increase in exposure to radiation in the area of medical service due to the rapid developments in diagnosis and therapeutic technologies. Nurses are exposed to radiation due to their tasks in a hospital, although the types of radiation to which they are exposed depend on their assigned departments. Exposure to radiation is dependent on various factors, but the overall exposure rates differ according to the department in which the nurses work and the length of their careers.

It remains controversial as to whether one's occupation has an

Copyright $@ 2016$ by Korean Society of Otorhinolaryngology-Head and Neck Surgery

This is an open-access article distributed under the terms of the Creative Commons Attribution Non-Commercial License (http://creativecommons.org/licenses/by-nc/4.0)

which permits unrestricted non-commercial use, distribution, and reproduction in any medium, provided the original work is properly cited. 

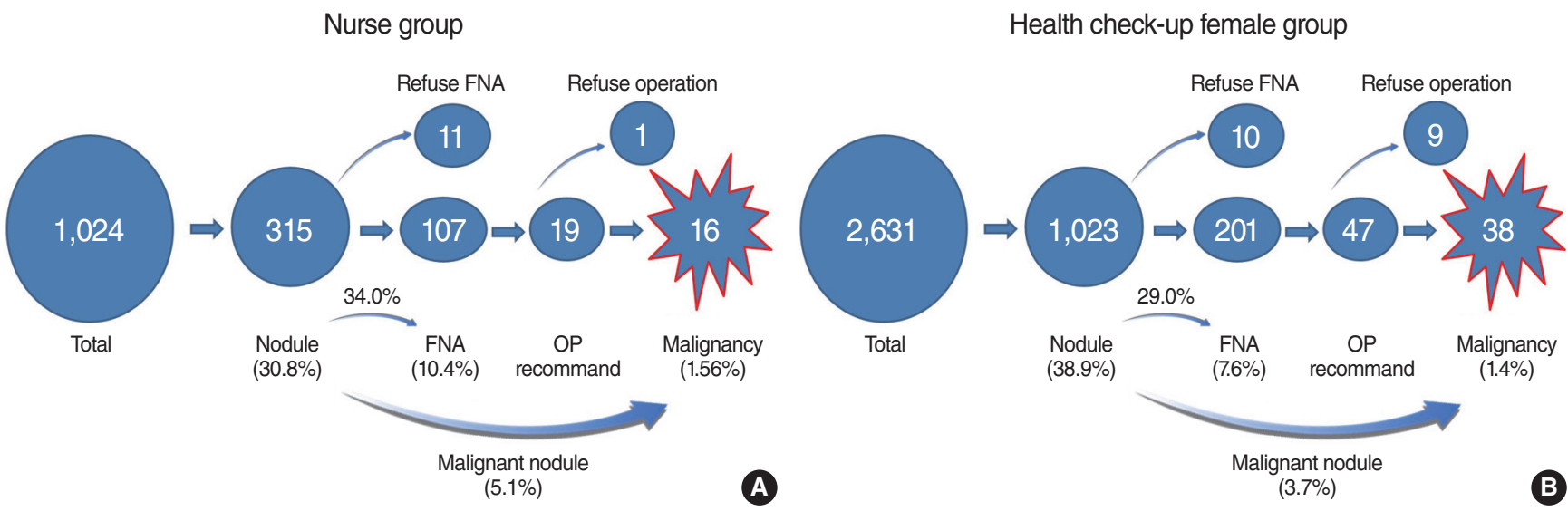

Fig. 1. The flow pathway of diagnosis and treatment of $(A)$ nurse group and $(B)$ health check-up female group. FNA, fine-needle aspiration; $\mathrm{OP}$, operation.

effect on the prevalence of thyroid nodules and thyroid cancer. Because radiation is generated from diagnostic equipment and therapeutic procedures in hospitals, there has long been a question whether working in a hospital can affect the prevalence of thyroid nodules and thyroid cancer. It is known that the radiation level detected in a hospital is higher than the radiation level to which the general population is exposed. However, few studies have examined the risk of working in a hospital in comparison to the risks faced by the general population.

In this study, we have investigated the existence of difference in the prevalence of thyroid nodules and thyroid cancer between nurses working at a single hospital and health check-up female, who had undergone a health examination at the same hospital during the same period

\section{MATERIALS AND METHODS}

The participants of the study were female nurses, who worked at a single hospital and female who were visiting the doctor for annual examination (who had undergone a health examination at the same hospital) during the period starting from January 2011 to December 2013. We checked both the groups for occupational career, any medical history, family history, height, and weight using questionnaire.

The exclusion criteria included presence of previous history

\section{H I G H L I G H T S}

- It is known that a great extent of radiation is emitted from the medical instruments used in hospitals and that radiation exposure can cause thyroid cancer.

- However, working in a hospital does not increase the prevalence of thyroid cancer in this study. of thyroid cancer or thyroid surgery, and history of head and neck irradiation. From the group of health check-up female, the nurses were excluded.

Finally 1,024 nurses (mean, 41.6 \pm 6.7 years; range, 24 to 56 years) and 2,631 health check-up female (mean, 48.3 \pm 10.2 years; range, 24 to 67 years) were enrolled for the present investigation.

Thyroid ultrasonography was performed using a real-time ultrasound scanner with a 10 to $12 \mathrm{MHz}$ linear transducer. Any abnormality was detected in the thyroid USG. Thyroid nodule was defined as lumps which arise within an otherwise normal thyroid gland. Thyroid cyst was defined as a fluid-filled cavity.

Nodule size was based on the largest nodule in cases of more than one nodule. USG-guided fine-needle aspiration \& cytology (FNAC) was performed in suspicious malignant nodule by one physician. The minimum size for aspirated nodules was $5 \mathrm{~mm}$ in diameter. In subjects with nondiagnostic and indeterminate cytology, repeat fine-needle aspiration (FNA) was performed after 3 months. After cytological diagnosis, operation was recommended for suspicious malignant nodule (Fig. 1).

\section{Ethics}

This study was approved by the Institutional Review Board of the Gyeongsang National University Hospital (GNUHIRB 201109-071-003).

\section{Statistics}

Statistical analyses of this study were performed using the SPSS ver. 15.0 (SPSS Inc., Chicago, IL, USA). Fisher exact tests were used to evaluate the correlation between the nurse and health check-up female. Chi-square tests were used to evaluate the correlation between the risk of malignancy and age, gender, multiplicity, and nodule size. Age is shown as the mean \pm standard deviation (SD). $P$-values less than 0.05 were considered significant. 


\section{RESULTS}

Prevalence of thyroid nodules in nurses and health check-up female by ultrasonography

The solid thyroid nodules were found in 315 nurses (30.8\%) and in 1,023 health check-up female (38.9\%). Among the health check-up female, the thyroid cysts were present in 499 female $(18.9 \%)$ and diffuse parenchymal changes were noted in 221 subjects $(8.4 \%)$. Otherwise, simple cysts were found in 53 $(5.2 \%)$ and diffuse parenchymal changes in 11 nurses $(0.1 \%)$ (Table 1).

The size of the solid thyroid nodules in nurse varied from 0.3 to $3.2 \mathrm{~cm}$. Thyroid nodules measuring $1 \mathrm{~cm}$ or less in diameter were found in 136 subjects (43.2\%), nodules measuring from 1 to $2 \mathrm{~cm}$ were found in 172 subjects $(54.6 \%)$, and nodules greater than $2 \mathrm{~cm}$ were found in 7 subjects $(2.2 \%)$. Multiple nodules were found in 95 subjects (30.2\%). Otherwise, the size of the solid thyroid nodule of health check-up female varied from 0.2 to $5.8 \mathrm{~cm}$. Thyroid nodules measuring $1 \mathrm{~cm}$ or less in diameter were found in 491 subjects (48.0\%), nodules measuring from 1 to $2 \mathrm{~cm}$ were found in 479 subjects $(46.8 \%)$, and nodules greater than $2 \mathrm{~cm}$ were discovered in 53 subjects (5.2\%). Multiple nodules were found in 339 subjects (33.1\%).

This difference with regards to thyroid nodules, cyst and parenchymal disease was significantly increased in health checkup female group $(P<0.05)$. The prevalence of thyroid nodules increased with age in both the groups.

\section{Prevalence of thyroid cancer in nurse and health check-up female}

Thyroid nodules were present in 315 nurses (30.8\%) and 1,023 health check-up female (38.9\%). Typically, based on USG-guided FNAC, 107 nurses (10.4\%) and 201 health check-up female
(7.6\%) had suspicious nodule. According to cytological results, 19 nurses $(1.9 \%)$ had suspicious malignant cytology (14 suspicious papillary thyroid carcinoma +4 suspicious follicular neoplasm +1 suspicious medullary carcinoma).

In the nurses group, 18 out of 19 subjects with suspicious malignant cytology underwent a thyroidectomy, and 16 nurses $(1.6 \%)$ were diagnosis with thyroid carcinoma (13 papillary carcinomas, 2 follicular carcinomas, 1 medullary carcinoma). Other two nurses were diagnosed with benign tumors. A single case with suspicious malignant cytology refused to undergo an operation (suspicious follicular neoplasm).

According to cytological results, 47 health check-up female $(1.8 \%)$ had suspicious malignant cytology, and 38 health checkup female $(1.4 \%)$ were diagnosed with thyroid carcinoma (36 papillary carcinomas, 1 follicular carcinoma, 1 Hürthle cell carcinoma, and 9 benign tumors) and they underwent a thyroidectomy. The other 9 health check-up female with suspicious malignant cytology were lost during follow-up. The follow-up was at least for 12 months period.

The overall prevalence of thyroid cancer was in 38 female (1.4\%) among the 2,631 female enrolled for health check-up, and in 38 female (3.7\%) among the 1,023 subjects with thyroid nodules. Otherwise, the prevalence of thyroid cancer was observed in 16 nurses (1.6\%) among the 1,024 enrolled nurses and in 16 nurses (5.1\%) among the 315 nurses with thyroid nodules.

The prevalence of thyroid cancer tended to increase with age, however no significance was noted in both groups $(P>0.05)$. Nevertheless, the rate of prevalence with thyroid cancer versus nodules and thyroid cancer was high in nurse group aged 30-39 years (Table 2). The rate was found to be independent of sex, occupational career, family history, body mass index, thyroid nodule size, and multiplicity.

Table 1. Ultrasonographic findings of the thyroid gland in 1,024 nurses and 2,631 health check-up female

\begin{tabular}{lcc}
\hline \multirow{2}{*}{ Characteristic } & \multicolumn{2}{c}{ No. of subjects (\%) } \\
\cline { 2 - 3 } & Nurse $(\mathrm{n}=1,024)$ & Health check-up female $(\mathrm{n}=2,631)$ \\
\hline Age (yr), mean \pm SD (range) & $41.6 \pm 6.7(24-56)$ & $48.3 \pm 10.2(24-67)$ \\
Family history (thyroid cancer) & 6 Subject & 14 Subject \\
Nodule size $(\mathrm{cm})$, mean \pm SD (range) & $1.27 \pm 0.89(0.3-3.2)$ & $1.45 \pm 1.07(0.2-5.8)$ \\
$<1$ & $136(43.2)$ & $491(48.0)$ \\
$1-2$ & $172(54.6)$ & $479(46.8)$ \\
$>2$ & $7(2.2)$ & $53(5.2)$ \\
Solid nodules & $315(30.8)$ & $1,023(38.9)$ \\
Suspicious nodule + fine-needle aspiration & $107(10.4)$ & $201(7.6)$ \\
Suspicious malignant cytology & $19(1.9)$ & $47(1.8)$ \\
Confirmed thyroid cancer & $16(1.6)$ & $38(1.4)$ \\
$\quad$ Cancer/nodule & $16 / 315(5.1)$ & $38 / 1,023(3.7)$ \\
Thyroid cyst(s) & $53(5.2)$ & $499(18.9)$ \\
Parenchymal changes & $11(0.1)$ & $221(8.4)$ \\
Normal & $645(62.9)$ & $888(33.8)$ \\
\hline
\end{tabular}


Table 2. Prevalence of thyroid nodule and cancer with respect to age in 1,024 nurses and 2,631 health check-up female

\begin{tabular}{rlcccccc}
\hline \multicolumn{2}{c}{ Variable } & $\leq 29 \mathrm{yr}$ & $30-39 \mathrm{yr}$ & $40-49 \mathrm{yr}$ & $\geq 50 \mathrm{yr}$ & Total & $P$-value \\
\hline Nodule/total & Nurse & $40 / 182(22.0)$ & $133 / 468(28.4)$ & $114 / 313(36.4)$ & $28 / 61(45.9)$ & $315 / 1,024(30.8)$ & 0.001 \\
& Female & $60 / 255(23.5)$ & $346 / 1,049(33.0)$ & $382 / 900(42.4)$ & $235 / 427(55.0)$ & $1,023 / 2,631(38.9)$ & 0.001 \\
& $P$-value & 0.730 & 0.083 & 0.593 & 0.217 & $0.001^{*}$ & - \\
Cancer/total & Nurse & $1 / 182(0.6)$ & $9 / 468(1.9)$ & $5 / 313(1.6)$ & $1 / 61(1.6)$ & $16 / 1,024(1.6)$ & 0.538 \\
& Female & $2 / 255(0.8)$ & $15 / 1,049(1.4)$ & $14 / 900(1.5)$ & $7 / 427(1.6)$ & $38 / 2,631(1.4)$ & 0.455 \\
& $P$-value & 1.000 & 0.506 & 1.000 & 1.000 & 0.762 & - \\
Cancer/nodule & Nurse & $1 / 40(2.5)$ & $9 / 133(6.8)$ & $5 / 114(4.4)$ & $1 / 28(3.6)$ & $16 / 315(5.1)$ & 0.877 \\
& Female & $2 / 60(3.3)$ & $15 / 346(4.3)$ & $14 / 382(3.7)$ & $7 / 235(3.0)$ & $38 / 1,023(3.7)$ & 0.568 \\
& $P$-value & 1.000 & 0.348 & 0.781 & 0.599 & 0.325 & - \\
\hline
\end{tabular}

Values are presented as number (\%).

${ }^{*} P<0.05$.

\section{DISCUSSION}

The possibility of chronic exposure to low-dose radiation in the working environment in hospitals has often been described in literature [20-23]. As the number of instruments emitting considerable amounts of radiation is increasing due to the development of medical instruments for the purpose of diagnosis and treatment, radiation from these instruments is a concern for the nurses, who use and maintain them. Vests or cervical guards made of lead are often used to avoid exposure to radiation, but these items are mainly intended to block intentionally emitted radiation. Based on the limited protective measures from all forms of radiations, working in a hospital is occasionally accompanied with fear of exposure to radiations in nursing occupation [21]. In particular, thyroid cancer, which is on a current drastic increase is related to radiation; but female nurses who may perhaps be concerned about their thyroids, have been unable to find an appropriate countermeasure as there have been no investigations on the effects of occupational radiation exposure at hospitals with respect to thyroid nodules and thyroid cancer. Therefore, we conducted a comparative study between nurses and general health check-up female in an effort to investigate whether working at a hospital affects the prevalence of thyroid disease in nurses.

The result of the present study showed that the prevalence of thyroid nodules was increased in health check-up female, however in general; no difference was noted in prevalence of thyroid cancer in both the groups. Interestingly, the rate of prevalence of thyroid cancer versus nodules was significantly high in 30-39 years old nurses. Furthermore, the number of thyroid nodules increased with increase in age. The prevalence of thyroid cancer was not proportional to the ages of the subjects. This indirectly indicates that thyroid nodules or thyroid cancer do not result from radiation, and conceivably indicate appropriate execution of preventive measures, such as shifting the work of a nurse who has worked for a certain period of time in a department associated with radiation or in an operation room where radiation instruments are used (where the possibility of radiation exposure is relatively high). Alternatively, this result may have stemmed from the relatively limited direct radiation exposure. Nonetheless, this issue should be investigated in further studies for an assessment of any correlation between dose and response as the female undergoing a health examination for abnormalities such as a nodule tend to undergo regular medical checkups. The ratios of thyroid cysts, parenchymal disease and thyroid nodule were higher in subjects who underwent a health examination compared to that in the nurse group. On the other hand, because as the nurse group in this study included all the nurses in the single hospital, selection bias was low in the nurse group as compared to the health examination subject group. Therefore, it can be assumed that the working environment in the hospital has no effect on the prevalence of thyroid nodules or thyroid cancer among the nurses.

The main limitation of the current study is the absence of accurate individual estimates of radiation dose. Individual measurements, however, have so far not been adequately computerized and available for epidemiologic analyses. A subsequent study is required to individually measure radiation exposure in a hospital and there is a need for prospective cohort study for determining relationship between radiation and thyroid cancer.

In conclusion, although there are many other parameters that should be taken into account, the result showed that working in a hospital does not increase the prevalence of thyroid nodules or thyroid cancer.

\section{CONFLICT OF INTEREST}

No potential conflict of interest relevant to this article was reported.

\section{REFERENCES}

1. Bomeli SR, LeBeau SO, Ferris RL. Evaluation of a thyroid nodule. Otolaryngol Clin North Am. 2010 Apr;43(2):229-38. 
2. Gharib H, Papini E, Paschke R, Duick DS, Valcavi R, Hegedus L, et al. American Association of Clinical Endocrinologists, Associazione Medici Endocrinologi, and European Thyroid Association Medical guidelines for clinical practice for the diagnosis and management of thyroid nodules: executive summary of recommendations. Endocr Pract. 2010 May-Jun;16(3):468-75.

3. Hegedus L. Clinical practice: the thyroid nodule. N Engl J Med. 2004 Oct;351(17):1764-71.

4. Tonacchera M, Pinchera A, Vitti P.Assessment of nodular goitre. Best Pract Res Clin Endocrinol Metab. 2010 Feb;24(1):51-61.

5. Brander A, Viikinkoski P, Nickels J, Kivisaari L. Thyroid gland: US screening in a random adult population. Radiology. 1991 Dec;181 (3): 683-7.

6. Brander A, Viikinkoski P, Tuuhea J, Voutilainen L, Kivisaari L. Clinical versus ultrasound examination of the thyroid gland in common clinical practice. J Clin Ultrasound. 1992 Jan;20(1):37-42.

7. Ezzat S, Sarti DA, Cain DR, Braunstein GD.Thyroid incidentalomas: prevalence by palpation and ultrasonography. Arch Intern Med. 1994 Aug;154(16):1838-40.

8. Rojeski MT, Gharib H. Nodular thyroid disease: evaluation and management. N Engl J Med. 1985 Aug;313(7):428-36.

9. Tan GH, Gharib H. Thyroid incidentalomas: management approaches to nonpalpable nodules discovered incidentally on thyroid imaging. Ann Intern Med. 1997 Feb;126(3):226-31.

10. Vander JB, Gaston EA, Dawber TR. The significance of nontoxic thyroid nodules: final report of a 15-year study of the incidence of thyroid malignancy. Ann Intern Med. 1968 Sep;69(3):537-40.

11. Choi SY, Woo SH, Shin JH, Choi N, Son YI, Jeong HS, et al. Prevalence and prediction for malignancy of additional thyroid nodules coexisting with proven papillary thyroid microcarcinoma. Otolaryngol Head Neck Surg. 2013 Jul;149(1):53-9.

12. Woo SH, Kim KH, Kim RB. Thyroid nodules with repeat nondiagnostic cytologic results: the role of clinical and ultrasonographic findings. World J Surg. 2015 Jul;39(7):1721-7.

13. Chung WY, Chang HS, Kim EK, Park CS. Ultrasonographic mass screening for thyroid carcinoma: a study in women scheduled to un- dergo a breast examination. Surg Today. 2001;31(9):763-7.

14. Belfiore A, La Rosa GL, La Porta GA, Giuffrida D, Milazzo G, Lupo $\mathrm{L}$, et al. Cancer risk in patients with cold thyroid nodules: relevance of iodine intake, sex, age, and multinodularity. Am J Med. 1992 Oct; 93(4):363-9.

15. Francis GL, Waguespack SG, Bauer AJ, Angelos P, Benvenga S, Cerutti JM, et al. Management guidelines for children with thyroid nodules and differentiated thyroid cancer. Thyroid. 2015 Jul; 25(7):716-59.

16. Gasent Blesa JM, Grande Pulido E, Provencio Pulla M, Alberola CandelV, Laforga Canales JB, Grimalt Arrom M, et al. Old and new insights in the treatment of thyroid carcinoma. J Thyroid Res. 2010 Apr;2010:279468.

17. Papini E, Guglielmi R, Bianchini A, Crescenzi A, Taccogna S, Nardi F, et al. Risk of malignancy in nonpalpable thyroid nodules: predictive value of ultrasound and color-Doppler features. J Clin Endocrinol Metab. 2002 May;87(5):1941-6.

18. Cho JK, Woo SH, Park J, Kim MJ, Jeong HS. Primary squamous cell carcinomas in the thyroid gland: an individual participant data meta-analysis. Cancer Med. 2014 Oct;3(5):1396-403.

19. Woo SH, Kim JP, Park JJ, Shim HS, Lee SH, Lee HJ, et al. Comparison of natural drainage group and negative drainage groups after total thyroidectomy: prospective randomized controlled study. Yonsei Med J. 2013 Jan;54(1):204-8.

20. Covens P, Berus D, de Mey J, Buls N. Mapping very low level occupational exposure in medical imaging: a useful tool in risk communication and decision making. Eur J Radiol. 2012 Sep;81(9):e962-6.

21. Igaki H, Nakagawa K. Radiological clinical practice and its safety in hospital. Nihon Rinsho. 2012 Mar;70(3):475-8.

22. SontWN, Zielinski JM, Ashmore JP, Jiang H, Krewski D, Fair ME, et al. First analysis of cancer incidence and occupational radiation exposure based on the National Dose Registry of Canada. Am J Epidemiol. 2001 Feb;153(4):309-18.

23. Zabel EW, Alexander BH, Mongin SJ, Doody MM, Sigurdson AJ, Linet MS, et al. Thyroid cancer and employment as a radiologic technologist. Int J Cancer. 2006 Oct;119(8):1940-5. 